\title{
TRANSFORMING TEACHER EDUCATION, AN ACTIVITY THEORY ANALYSIS
}

\author{
Jane McNicholl $^{1}$, Allan Blake ${ }^{2}$ \\ ${ }^{1}$ University of Oxford, UK; ${ }^{2}$ University of Strathclyde, UK
}

\begin{abstract}
This paper explores the work of teacher education in England and Scotland. It seeks to locate this work within conflicting socio-cultural views of professional practice and academic work. Drawing on an activity theory framework that integrates the analysis of these seemingly contradictory discourses with a study of teacher educators' practical activities, including the material artefacts that mediate the work, the paper offers a critical perspective on the social organisation of university-based teacher education. Informed by Engeström's activity theory concept of transformation, the paper extends the discussion of contradictions in teacher education to consider the wider socio-cultural relations of the work. The findings raise important questions about the way in which teacher education work within universities is organised and the division of labour between schools and universities.
\end{abstract}

Keywords: teacher education; academic work; cultural historical activity theory; division of labour; transformation.

\section{Introduction}

The research reported here explores the work of pre-service or initial teacher education (ITE) in two of the four home nations of the UK, England and Scotland, where, despite different educational systems, university-based teacher education is perceived to be under threat. In England, work-based routes into teaching - such as the Graduate Teacher Programme (GTP), Teach First and, most recently, School Direct - have not only proliferated, but are increasingly endorsed by the UK Government as a pragmatic solution to easing the cost-overload of ITE. These are programmes of study in which schools increasingly take over the work of educating pre-service teachers and which are considered by many involved in university-based teacher education to be leading to a reduction of the role of higher education in ITE. Though, in 
Scotland, the recommendations of the Scottish Government's report on the future of teacher education (Donaldson 2011) have focused on enhancing existing partnerships between universities and schools, the roles within these partnerships are presently being redefined to give schools joint responsibility for the assessment of student teachers during placement and, in some cases, to extend the period of student placement in school.

This diversification, some might say fragmentation, of teacher education provision and expertise in the UK has coincided with equivalent changes in the United States, where impatience with traditional teacher preparation programmes has led to shorter courses and a movement away from university to school based models of preparation. The Teach For America programme, for example, has been suggested to improve exam results in schools that serve socially disadvantaged children through appointing academically talented graduates (Xu et al. 2011). But with less than a third of TFA recruits staying in teaching for longer than the two years that are required by the programme, the political arithmetic of teacher retention remains surprisingly little explored.

Within this complex and sometimes contradictory mix of policy change, higher education (HE) based teacher educators have come to occupy an undeniably difficult position. They are caught increasingly between an apparent 'rush to practice' on the one hand, and mounting anxieties about research output and economic competitiveness across the HE sector as a whole on the other. Though we agree with Darling-Hammond (2006) in thinking that teacher education has a central role in the improvement of educational systems and that universities have an important contribution to make, the research reported here is not simply a defence of the status quo. The premise, rather, is to explore the potential for the organisational development of teacher education; to think about the ways in which teacher education might be transformed in terms of partnership working with schools and as a form of higher education.

\section{The Work of Teacher Education research}

A transformative perspective on teacher education requires an empirical understanding of the cultural and historical practices that frame the work (Avis 2009). While there is a small but growing literature on the induction and identity-transformation of teacher educators, the role of 
institutions in structuring the work is either implicit or overlooked entirely. The Work of Teacher Education (WoTE) research project has therefore sought to investigate the practical activities and material conditions of HE-based teacher educators' work in England and Scotland. The project worked with a small sample of 13 teacher educators from institutions in England and Scotland in trying to answer the questions what do HE-based teacher educators do? What are they working on - and why? We interviewed and observed participants at work and asked them to complete work diaries at two different points in our year-long study. We made both quantitative and qualitative analyses of our data.

To set the context for the WoTE study, this paper first of all develops an understanding of the historical evolution of the different education systems, including the professional cultures that have arisen and the tensions that exist in conflicting socio-cultural views of practice and research. Thereafter, drawing on a cultural-historical theoretical framework that integrates the analysis of these contradictory discourses with the study of participants' practical activities including the material artefacts that mediate their work - the paper offers a critical perspective on the organisational practices in which teacher educators participate. Informed by Engeström's (1999) activity theory concept of transformation, the paper extends the discussion of contradictions in teacher educators' local practices to reconsider the wider social and cultural relations of the work.

\section{Teacher education in England and Scotland: a historical perspective}

Teacher education in England and Scotland has evolved along similar lines. In both countries, throughout the 1970s, 80s and 90s, independent teacher training colleges were incorporated into polytechnics and universities. Following the Further and Higher Education Act of 1992, which afforded polytechnics university status, ITE became located in both 'old' (pre-1992) and 'new' (post-1992) universities. In England, partnership working between universities and schools has developed according to statutory principles, whereas, in Scotland, ITE is characterised by a series of cooperative relationships between schools and universities (Christie et al. 2004). During this time, the Government regulation of ITE in each country has also expanded, resulting in frequent shifts in policy - sometimes characterised as a form of policy hysteria (Stronach and Morris 2009) - as well as the introduction of professional standards and formal induction 
schemes for newly qualified teachers. In England there are now over 200 teacher education 'providers' who compete for the more than 30,000 student teacher places each year (Mahony and Hextall 2000). The allocation of these places to English providers is overseen by the Teaching Agency on the basis of quality judgments provided by the inspectorate, Ofsted. By contrast, the training of teachers north of the border remains exclusively within the domain of traditional university-based undergraduate and postgraduate programmes. Smaller in scale, the majority of this provision is managed by Education Departments or Faculties in just seven universities.

A further distinguishing feature of the system in England has been the Government's determination to loosen HE's 'stranglehold' on teacher education (Iven 1994). The result has been a diversification and increasing flexibility of provision, with school-centred and employment based routes into teaching (e.g. GTP and Teach First) having been introduced by the previous Government, and School Direct by the present coalition administration (DfE 2010; 2011). It should be noted however, that the majority of teachers in England continue to receive their training on traditional university-based, postgraduate courses. But as Teach First and School Direct grow in scale - and with the related funding being allocated to schools at a cost that is reported to be less to Government than $\mathrm{HE}$ - nervousness about the future of universitybased ITE in England intensifies.

In Scotland, the diversification of provision has tended to be restricted to the creation of parttime, flexible learning routes on traditional Higher Education Institution (HEI)-based programmes (Menter et al. 2010). A background of reduced university funding and a reduction in the number of student teacher places in Scotland has led to early retirement / voluntary severance schemes which have facilitated the departure of HE-based teacher educators in large numbers and reduced the range of subjects taught in certain cases. Some universities are moving teacher educators on to 'teaching only' contracts if they are not research active at a high enough level. There is thus a question of whether the HE system or individual HEIs in Scotland will continue to recruit practising teachers for teacher education work, individuals with the required professional qualifications and experience but who also need support in becoming active researchers. The response to the Donaldson (2011) report on teacher education in Scotland is resulting in changes to practice that promote closer partnership and collaborative working with 
schools (e.g. Menter \& Lowden, 2012). In a move which has provoked contestation among many involved, some universities are locating tutors in schools during periods of student placement. Donaldson's rhetorical appeal is said to be persuasive, even if his recommendations have little foundation in empirical evidence and tend to adopt an ideological stance on how things could be improved. Altogether, in a number of education departments in Scotland there now exist anxieties similar to those experienced by English colleagues (Christie et al 2012).

\section{The teacher education workforce}

The teacher education workforce is composed primarily of qualified teachers who tend not to have $\mathrm{PhDs}$, the conventional entry qualification and route into academic life, but have much valuable experience as teachers, experience that is necessary to do the job of teacher education. The UK Economic and Social Research Council's (ESRC) Demographic Review of the Social Sciences (Mills et al. 2006) showed that teacher educators are a relatively mature workforce: more than half of academic staff in Education departments were aged 50 or over at the time of the review, and they also comprised the smallest proportion across the social sciences who were under 34 years. Research suggests that in comparison with colleagues elsewhere in the university, the occupational experience of teacher educators has engendered a discrete professional culture. For example, studies in Europe and the US have identified differences in job security; teacher educators are less likely to have secured tenure (Tierney 2001; Kosnick and Beck 2008) and they are much more likely to be part-time workers (Berger and Kostal 2002). In terms of professional identity, teacher educators frequently self-identify as practitioners rather than as academics (Murray 2002). Others would argue that it is institutional conceptualisations of the teacher educator as a 'super teacher' that act powerfully to frame the professional identities of new teacher educators (Ellis et al. 2012). As with the higher education workforce generally, the teacher educators are far from being a homogeneous group (Enders 2000). Despite this, the term teacher educator in much of the current research literature is treated as an undifferentiated category. Moreover, where difference is recognised, few studies have looked at either the nature of this differentiation, how it influences the work of teacher education or considered the role of institutional factors in shaping the work.

\section{Teacher education as academic work?}


Academic work is usually defined as the labour of people employed as lecturers or professors in university settings. The research literature on teacher education as a form of academic work is underdeveloped; the little that does exist shows evidence of a tension between teaching quality and research productivity. This tension is apparent across the HE sector as a whole - though, perhaps because there tends to be little acknowledgement by universities of teacher educators' different backgrounds and research training requirements, it is particularly visible in the performativity of departments of Education (Cuban 1999; Clifford and Guthrie 1988; Tierney 2001; Slaughter and Rhoades 2004).

This tension became an important focus in our research. For not only is developing a research profile an important signifier of academic work, university funding is partly determined by audits of research productivity and quality. Studies from across the world have shown that engaging in research and scholarship can present a challenge to many teacher educators; in the UK two thirds of education academic staff were classified as not 'research active' in the demographic review by Mills et al. (2006). Our own research has suggested that time for research may be 'squeezed in', partly because teacher education is high in time to labour (Ellis et al. 2011). In one sense, this may be seen as inevitable and associated with the expectation of the high quality of teaching and the effort that is necessary to demonstrate attainment of statutory professional requirements and standards. In another, contradictory expectations are played out between research productivity and professional credibility, with the teacher educator being produced as a hybrid category of academic worker (Ellis et al. 2012).

The professional credibility and sense of self of some teacher educators has been found to remain within their identity as practitioners rather than academics (Murray 2002; Murray 2005). For others, the challenge is in making the transition from ex-teacher to academic (Ducharme 1993; Acker 1997; Harrison and McKeon 2008; Kosnik and Beck 2008; Schuster and Finkelstein 2008), particularly in the light of the rather limited induction into research that is generally available (Murray 2005; Murray and Male 2005; Murray et al. 2009). The prevalence of activities directed at creating and maintaining the networks of relationships between teacher educators, teachers and students that characterise partnership teacher education (Ellis et al. 2011) has also been shown to constrain research activity (McNamara et al. 2008). The hybridity 
of the teacher educator might equally be an effect of the requirement to work within intensively monitored and inspected regimes, and so teacher educators 'become busy in such practicalities and less likely to become active researchers' (Day 1995, 365).

This limited engagement with research and scholarship has meant that teacher educators are often discoursed as 'semi-academics' who occupy a lesser position in higher education (Duchamre 1993; Russell and Chapman 2001; Murray 2002). Because teacher education is 'defined as a service profession' (Dillabough and Acker 2002, 234) it is vulnerable to influence from Government. The teacher educator is therefore continually mediating government policy and changing initiatives, which has the effect of exacerbating the discipline's apparently inferior status in higher education because, unlike many other university subject areas, it is less independent in its responsibility for the accreditation and administration of degree programmes.

Research by Maguire (1994) has further suggested that teacher education work is a gendered process. It is 'women's work' (ibid.), the 'domestic labour' of Education Departments (Liston 1995) which also tend to have a higher representation of female employees than other subject areas. If, as Acker and Dillabough $(2007,298)$ argue, 'the gendered division of labour' has led to workplace cultures that are split along gender lines, the result may be a reproduction of professional disadvantage across education and gender boundaries given that the sensibilities of fratriarchal performance are said to remain the operating paradigm within HE more generally (Harley 2003).

Given the tensions between the teacher educator's perception of what is required to maintain teaching and the university's requirement to generate research income, between teacher educators' acquired professional status of a typically high level and their low status as novices in academic life (mainly associated with the absence of a research profile), and between the independence of the teacher educator as an academic and as a member of a profession that is accountable to professional bodies and government initiatives, it is unsurprising perhaps that an 'array of intellectual, cultural and economic trends are converging so as to question' (Hartley 2009, 139) whether the work of teacher education is appropriate for HE, and economic in labour and resource. 


\section{Research design and methodology}

In this study, we have been motivated to reveal the extent to which teacher educators' work involves cultural and historical processes that underpin both their practical activities as individuals - the tasks and the material conditions that constitute their work - and their professional representations as members of an academic organisation. From this perspective, rather than focussing on the reflexive consciousness of the individual worker, it has been necessary to recognise work as being an activity embedded in social contexts and thus available to interpretation as a form of participation in these contexts (Reeves and Boreham 2004). The design of our study was therefore framed by culturalhistorical activity theory (CHAT), a philosophical position which takes a 'deeply contextual' approach to 'understanding historically specific local practices, their objects, mediating artefacts, and social organization' (Engeström 2005, 307-8). Human activity is then the unit of analysis within a CHAT framework. Activity in this context refers to the action of human subjects on their social worlds, and may be identified by the deliberate purpose or object to which such action is directed. Object, in a CHAT analysis, might therefore be understood as the potentially shared problem or societally significant goal that humans are working on or towards (Engeström 1999).

We tend to agree with Foot (2001) in thinking that Engeström delineates activity as a unit of analysis for 'understanding a larger flow of human life'(9), with the result that specific activities can be analysed according to the actions - the component practices which are subordinate to conscious goals (ibid.) - by which an organisation is discursively enacted. These actions represent facets of the social and historical configuration of an activity and are often portrayed graphically in the triangular representation of an activity system (Engeström 1999). From this perspective, the object of the work of a university-based teacher educator (the subject) might be the student teacher and his or her learning. The outcomes would include student teachers' successful completion (or indeed failure) of the programme of study, which is also likely to include an episode of professional placement in school. The tools involved might range from the seemingly commonplace (teaching rooms and materials and so on) to a series of 'partially internalised diagnostic' teaching-related concepts and methods (CRADLE $2009 \mathrm{np}$ ). The community comprises university-based staff as well as teachers in placement schools, with the division of labour establishing the roles, responsibilities and powers of the teacher educator in relation to the other members of the community. The rules would account for 
the timeframe and environments in which the programme is located, as well as the measurement of outcomes, and the criteria for success and failure. In tracking these forms of action, activity system analysis affords an understanding of human activity that is situated in a collective context, where each activity system reveals the social and material resources that are at play in the activity system (Engeström 1999), including the internal contradictions that may result, and where the relationships between different activity systems can further be represented by a series of concomitant or indeed conflicting triangular interpretations (Engeström 1987).

According to Leont'ev (1978), the most important factor in identifying the object of activity is the 'object motive', a particular point of view and set of parallel values which direct the participation of subjects in an activity system (Edwards 2011). The concept of 'object motive' is thus helpful in reaching an understanding of the different ways in which a teacher educator and a teacher in school might each interpret the developmental task of the same student teacher (ibid.). That is to say, their respective practices may each be 'driven forward by a slightly different "object motive"” (ibid. np), though they might collaborate in the same object and intended outcome. For the present study however, involving a sample of teacher educators based in English and Scottish HEIs, a CHAT perspective affords an analysis of multiple motives working on the same object and distinguishing a diversity of motives among those (collectively) in the subject position.

As participants in an activity system rarely talk in terms of how they construct and interpret the object of their activity, it is nonetheless possible for researchers to understand how the object is being construed by analysing how participants use the tools that inform practice (Stetsenko 2005). Leont'ev, in Activity, consciousness, and personality (1978), explains that a large part of the knowledge and practice of an organisation is bound up in its artefacts, which become 'significant constituents of its culture' (Reeves and Boreham 2004, 470). From a CHAT perspective, tools can be broadly material (or practical) - our focus in this research - or psychological. The focus of this paper is not only then on the material artefacts employed by teacher educators, but also on the project's use of a participatory research design to understand these artefacts in a Vygotskian sense as tools that mediate human action in their social worlds (Vygotsky 1986). For Wertsch (2007), this mediating function of tools also demonstrates the 'foundation for another of Vygotsky's theoretical goals, namely building a link between social and historical processes, on the one hand, and individuals' 
mental processes, on the other' (178). In other words, tool-use reveals something about the cultures within which tools have developed as well as the thinking of those who work with them and, further, highlights the relationship between these two social and historical processes.

\section{Limitations}

Activity theory as an empirical method is not without limitations. It is interesting to consider, for example, that the model can be made to fit almost any activity but that it is most, or perhaps only plausible (Bakhurst 2009) when tracing straightforward approaches to specific, predictable ends (Martin \& Peim 2009). It could therefore be objected that activity theory is not after all a theory but rather a general schema (Bakhurst 2009), whose explanatory power is most evident in relation to activities that are carried out by self-identifying subjects who have a well defined object and a clear sense of the tools that might be applied (ibid.). This may be an additionally important deliberation in the context of activity theory's ambiguity towards conceptualising individual agency (Edwards and Daniels 2004). Precisely because activity theory is limited to interpreting specific, local practices, the macro socio-political structures that position subjects, particularly in terms of the division of labour, (Martin and Peim 2009) tend to be understated in activity system analysis. Thus, social class, gender, race, even the influence of one's own psychology are not afforded a 'distinctive ontological status' (Hartley 2009, 146), but tend to be subordinated within the configurations of an activity system. The potential of activity theory to function as a transformative tool may then be fractional if the broader character of human agency is not recognised in the analysis to have properties that originate independently of the expression of the system. Martin and Peim $(2009,134)$ too are critical of activity theory's 'inability to draw attention to notions of power and social antagonisms [...] that are expressions of macro-social and political context'. For example, the empirical conceptualisation that we have elsewhere developed (Ellis et al. this issue) to suggest that the division of labour within HE education departments is formative in structuring teacher educators as a proletarianised class of worker depends upon a Marxian analysis of academic capitalism employed in conjunction with an activity theory approach. As Bakhurst (2009) notes, in order to abstract the politics of representation from the ambiguity of everyday life, the researcher must be prepared to work their way into the system, 'to see how things look from the perspective of the various agents, and to sense the forces that influence their perceptions and their actions' (207). 


\section{Data generation and analysis}

Through the ESCalate email newsletter, the UCET email list of heads of department and the University of Oxford Department of Education website, we constructed a convenience sample of 13 teacher educators. In our call for participation, we explained that we were looking for HE-based teacher educators in England and Scotland who had direct responsibility for working with student teachers and schools and that there would be a participatory dimension to the research that would involve participants in an analysis workshop and dissemination activities. The breakdown of the sample is shown in Table 1 below.

\section{Insert Table 1: The Work of Teacher Education research sample - here}

This table indicates whether the participant worked in a 'new' university or HEI, in an 'old' university or in one of the new type of further education (FE) colleges that undertake graduate work. The highest qualification column indicates whether the participant's highest academic qualification is doctoral (D), a master's (M) or a bachelor's degree (B) and the research active column identifies those participants who were entered in the 2008 Research Assessment Exercise and/or who were working towards submission in the 2013 Research Excellence Framework. A range of subjects are indicated and, although there is a bias towards the secondary phase, 5 of the 9 secondary teacher educators worked on primary programmes too. Though not intended to be representative of the population of HE-based teacher educators in England and Scotland, the gender balance, levels of experience and expertise, and type of institution, are broadly reflective of the demographics for the sector (HESA 2009; Mills et al. 2006; HEFCE 2009a, 2009b).

Although the number of participants fell just short of the range of 15-20 that is recommended for theoretical sampling (Creswell 2002), it was large enough to afford a deep, case oriented analysis of the experiences of a cross-section of teacher educators, drawing on a complementary blend of data collection, including documentary evidence, participant observation and interviews. In view of the relatively small sample size, the study does not claim to generalise to the wider population of teacher educators, but instead offers a particular theoretical perspective on the experience of 'education academics upon which the UK's wider claim as a world-leader in research is partially based' (Holligan et al 2011, 732). The empirical conceptualisation that we have developed also appears to 
resonate with the experiences of teacher educators in other national contexts, such that the project is being replicated by researchers at the Australian Catholic University in Melbourne and the Universities of Otago and Auckland in New Zealand. Early results from these related studies mirror many of our project's findings, with positive implications for the credibility, confirmability and transferability of interpretations and conclusions (Onwuegbuzie and Leech 2007).

Throughout the 2009-2010 academic year, we generated qualitative and quantitative data with our participants in the following ways: semi-structured interviewing, work diary reporting, ethnographic style observation in the workplace (or 'work shadowing'), and a participatory data analysis workshop. This mixed-methods approach was designed to explore the daily practical activities of our sample of teacher educators, including how individuals talked about their working lives, and how the material artefacts they used mediated these practical activities and shaped their interactions with students and significant others. Having addressed elsewhere our view of the work of teacher education in relation to the perspectives, practical activities and balance of job dimensions that were revealed in interview and through work diary accounts (Ellis et al. 2011), our focus here is on the analysis of observational data that was undertaken with participants at the project's workshop. Data generation - 'work shadowing' All participants were observed for a period of one working day by a member of the research team. Participants were asked to choose a 'typical' day for this activity - typical in terms of the work planned at that time of year - during the period October 2010 to January 2011. A member of the research team met the participant at the start of their working day and stayed with them until they left work. The researchers made field notes, including some near verbatim reconstructions of spoken interaction and took photographs to record in words and pictures the material conditions of participants' work, as well as the range of tools that were employed.

The data collected showed that in all but one case, the artefacts came from the professional context and comprised textual artefacts such as lesson observation forms (e.g. Brock, Coodle, Davis) and exam papers, marking schemes and examiners' reports (Hale); a curriculum policy document used in student teacher lesson planning (Hacker); use of software for an interactive white board was also observed (Brooks); and other items such as puppets (Gresham), large furry dice (Alloway), a tent (Gould), historical artefacts from museums (Duff) and mathematical shapes cut out of coloured paper 
(Monk). The only artefacts that might be construed as emerging from an educational research context were two transcripts of classroom interaction copied onto different coloured paper introduced by Brooks in a session on Assessment for Learning (AfL).

\section{Data analysis - the participant workshop}

Field notes and photographs from each observation were written into narrative form by each researcher. These verbal/visual narratives were coded using categories derived from CHAT (e.g. Engeström et al. 1999, Cole 1996), specifically the tools or artefacts that were the focus of our observations in the field; the way in which these tools were being used by teacher educators and student teachers (what they were mediating); and for what ends (the potential object of the activity). Attention was also given to the social organisation of the practical activities in which the teacher educators were engaged - how the work was organised and between whom (the division of labour and the social rules or conventions).

Seven of the teacher educators volunteered to attend the workshop along with three members of the research team. Prior to the workshop, each of the participants was emailed a transcript of their interview, a statistical summary of their work diaries and a copy of our field notes from observing them. At the workshop, a statistical summary of the work diary data was presented first, followed by a brief introduction to CHAT which showed how to draw on the concepts of rules, community and division of labour developed by Engeström and his associates (1999). An analytic discussion of excerpts from the observation data (field notes and photographs) then took place with the consent of the participants with whom the data had been generated (they were also present). The research team's intention was to do more than seek respondent validation of their interpretations but to work with the participants in extending the analysis of data. The aim was to generate rich data on the interactions and contradictions involved as participants made visible their work, moving between actions and activity systems. Moreover, to look at these contradictions in relation to the function of the material artefact within the activity system - was it functioning as a tool mediating the learning of student teachers or as a rule, as an organisational device; in other words as a behavioural norm or expectation. 
The analysis centred on the actual or potential contradictions emerging in the participants' interactions shaped by - and shaping - the activities observed. Engeström is somewhat vague (Bakhurst, 2009) on the properties of contradictions in activity systems, though their analysis is indicated as the primary means of transforming or producing new forms of work activity (Avis, 2009). That is to say, new forms of activity develop as participants work to overcome contradictions in the system. Avis (ibid.) further suggests that Engeström's discussion of contradictions in activity systems is drawn from the social antagonisms that are said to surround (the division of) labour and the appropriation of value within capitalist systems. Somewhat by extension, the role of contradictions in raising our participants' consciousness of their cultural contexts thus arose in questions about the way in which the work of teacher education within universities is organised and the division of labour between schools and universities in systems that involve a school-based form of pre-service teacher education where there is an almost immediate expectation of minimally competent practice.

An example in the data was the use of the Scottish Curriculum for Excellence policy document in student teacher lesson planning that was assessed by Hale during a school visit that we observed. Curriculum for Excellence (CfE) as a policy had been promoted within the HEI as a means of working on important kinds of learning beyond the narrow demands of curriculum subjects. In one school, the student teacher had meticulously referenced each phase of the lesson to sections of the Curriculum for Excellence framework. In the interaction following the lesson (the de-brief/feedback), the teacher educator tried to suggest that $\mathrm{CfE}$ was not intended to be used in this way and was rather a higher level set of expectations that were useful above the level of individual lessons. This suggested that an artefact that is employed in the professional cultures of schools, when subjected to examination for pedagogical purposes in a HE context, may not easily reveal its conceptual underpinnings if student teachers bring different and perhaps more instrumental motives to bear on their perceptions. It was this dynamic tension between material artefacts functioning as tools or rules that we explored in order to better understand the work of teacher education and it is to these negotiations that our analysis now turns.

\section{Analysing artefacts in use: what are they mediating and why?}


In the following, we examine a segment of the data from our field notes which shows a material artefact being used in activities intended to promote student teachers' learning. In seeking to understand how material artefacts/tools mediated the activities of the teacher educators who we observed, particularly in relation to the object of activity, the analysis of this data by participants at the workshop was guided by Kaptelinin and Miettinen (2005) in focusing on the use of the tool, the negotiation of its meaning among those who participate in the processes of mediation, and the social structures that afford and constrain these negotiations. Wertsch (1998) emphasises the materiality of mediational activities in the work of organisations, noting that "without such materiality, there would be nothing to act with or react to and the emergence of socio-culturally situated skills could not occur' (31). With the CHAT analytical framework in mind, participants at the workshop were therefore encouraged to discuss activity systems as being configurations within which people were undertaking some work, using certain tools and types of mediation within a particular kind of social organization, where elements of the work are apportioned to different groups of people. In this way, participants were asked to consider what problem (or object) was being worked on and why, and how the people involved were acting with and reacting to the artefact in question.

\section{An artefact in use: a lesson observation form of standards for qualified teacher status (QTS)}

A lesson observation form of standards for qualified teacher status was introduced at the workshop, accompanied by field notes recording its use:

9.10am: Davis leaves for a school visit to observe a PGCE Secondary Science student who is two weeks into her first school placement. The lesson begins at 10am and Davis is ready at a bench in the Science lab with various forms and extracts from handbooks. Davis is writing a running record of the lesson, very neatly, onto a lesson observation form. She moves only once to interact with the children (a Year 8 group) and then returns to the bench to continue writing the running record. I notice she writes 'Don't allow interruptions. Ensure clear boundaries - prevents fragmentation'. 
10.44am: the lesson is ending and Davis now starts writing a 'general comments form' about the lesson. The form is carbonated in triplicate: white for the student teacher; yellow for the mentor; pink for Davis herself.

10.45am: break time and Davis feeds back to the student teacher in the Science lab with the student teacher's mentor present. The mentor has also completed some observation forms but the conversation is dominated by Davis with occasional, short responses from the student teacher. Davis begins by reading through her completed observation form. The break ends and the mentor has to teach. Davis and the student teacher continue the conversation in a Science prep room. Davis continues to complete paperwork as she talks. By now, she has completed a lesson observation form, a general comments form, a link tutor visit form and a link tutor discussion prompt sheet. Prompted by the latter, she asks the student teacher questions: 'are you collecting evidence? You need to collect evidence. You've got some evidence here, haven't you? [Pointing to parts of the teaching file.] These forms are evidence'.

In this example of a textual artefact in use, the lesson observation form is being used in ways that suggested both an effort to stimulate student teachers' learning through reflection on their practice and as a means of providing evidence for institutional quality assurance regimes. At the workshop, Davis suggested of the object-motive for this artefact that there are 'many different things that you're working on', depending on 'the context, or the student, [or] the subjects [...] involved'. At times, it seemed that the artefact was mediating work on two different objects student teachers' learning as well as the quality assurance of partnership processes - so that, in effect, teacher educator and student teacher were participating in two different activity systems simultaneously.

At the workshop, Davis identified an additional object that might be enacted in the context of the school visit:

I'm just thinking [about] another object being worked on, because we would say part of our role is professional development for our mentors when we go in. So there's 
completely another thing going on because [...] you're gauging where they're at with their mentoring with your student. Then you're trying to help them ... there's another dimension being added to our job at that time.

Earlier, we suggested that the concept of 'object motive' may be helpful in understanding the different ways in which a teacher educator and a mentor might each interpret the developmental task of learning to teach, including the question of the informed judgement of just when a particular beginner may be ready to engage in a more sophisticated pedagogy. That is, their respective practices may each be influenced by different object motives, though they might collaborate in the same object and intended outcome. For example, when interviewed, Duff exemplified this distinction in what he interpreted as the high accountability of the school environment, contrasting his own more 'nurturing' approach to observing teaching with that of 'some teachers who mentor our students [and who] have... I don't quite know how to express it, but a fanatical desire to only allow the very, very best teacher in their eyes to pass'. Duff's reflection shares with Davis a motive not only to show awareness of the more instrumental forces in contemporary teacher education, but to find a means perhaps in the social organisation of the work to compensate for them. Potentially, this compensatory function of the work is suggested by Davis in her identification of the added dimension of the job - the professional development or 'help' that may be required by mentors in their work with students, and the subtle evaluation by Davis of the quality of that mentoring relationship - 'gauging where they're at' - in the context of the quality assurance processes of the school-university partnership. This opens up questions about the social organization of the work between schools and universities, including the degree to which the object of a teacher educator's activity may be dynamically constructed according to the activities of the other members of the community involved (Kaptelinin and Miettenen 2005), each with their own objects, motivated in this example by the burdens of quality assurance that were observed by many in our sample.

In addition to multiple objects for action, contradictions may also arise in the ways in which tools and their affordances are used: if the use is markedly different to the original purpose, for example. In the discussion at the workshop, a contradiction in the use of the lesson observation form was identified by Lenton, a teacher educator in Scotland. Working in a less heavily 
regulated context, Lenton's suggestion is that the possibilities for action may be 'constrained' if the use of a lesson observation form is simply viewed as a rule of participation in a school visit by a HEI tutor:

Drummond: I thought there was quite a lot of rules, in that you know there's a procedure which Davis is following. And clearly there is no time to deviate from this procedure.

Lenton: Yeah, and these four forms that need to be filled in, they look very constraining.

Davis: The one that's missing is the general comment form, which is a blank piece of paper. So that's where you've got your freedom, whereas this one here is about commenting on the standards per se. But you're right, I mean there are four ... and I think a lot of this is Ofsted driven. And if it wasn't for Ofsted I would be quite happy to go in with this [the general comment form]. Just jot down notes and then at the end of it say: 'There you are, off you go, that's my advice to you for this lesson'. But we are all of us under the Ofsted framework, as you know: how do you prove... what targets have you set for your students... how have you graded them against the standards? And it's all driven by Ofsted.

In this analysis by the teacher educators at the workshop, the lesson observation form is interpreted as a statutory quality assurance requirement or rule with which they have to comply, rather than as a tool for mediating the reflection of the student teacher. In other words, the agency of the teacher is regarded as being constrained by the social organisation - by the mediating tools - of the work (Hartley 2009).

This contradiction in the affordance of the lesson observation form occurs because it is constructed by the subject (the teacher educator) as an administrative demand which meets the requirement of one of the members of the community (Ofsted) in the activity system, rather than as an artefact useful for engaging the object of the activity (Foot 2001). This example is also useful in demonstrating that the affordances of tools designed (in this case) for student teacher learning, are in important ways matters of perception. The meaning of lesson observation forms 
or policy documents is not intrinsic to the tools in question and their function is not determined by the historical contexts of their evolution. Rather, the meaning and the potentially mediating function of the tool is only realised when the participants perceive them in relation to a potentially shared object. If the object is perceived as compliance with the requirement to meet specified standards then the cultural-historical meaning of the policy tool is unlikely to be realised in the activity of participants.

The tension between the construction of the lesson observation form as both a tool and a quality assurance requirement is significant for another reason: it reveals Davis' expertise in mediating abstract knowledge in the course of an intense focus on practice. Later in the same discussion, Davis contrasts the 'mechanistic' emplotment of the lesson observation form with an approach to teacher education that is nuanced and individual, as both a fundamental element of human being and that which tends to be absent from the solipsism of policy:

I've been struck by the different things you need to say to our trainees at different times. And each year I've found there's been a student who technically should be quite good, who's planned a lesson well, who has the subject knowledge to deliver a lesson, but then it's like they're not in the room. Even though they're talking and doing things, they're so dislocated from their own emotions whilst they're teaching. And actually that's an incredibly difficult thing to talk about, because you're really talking about your gut feeling and how it felt for you to be in the room with them and to get them to see what you're seeing and name what's happening... which is why they're struggling to deliver, when actually they're working hard and they're doing all the things they should be doing, but they're falling completely flat and the kids don't like them. It's ever so difficult to talk about that because it's very deep psychological stuff and it's quite nebulous. And I think those conversations are incredibly difficult, basically kind of unpicking bits of their emotional background really delicately and really carefully and over a long period of time in tiny steps for them to reach some sort of point of integration. And you can only do that because of the way that you work with them based on your own expertise. 
Here Davis alludes to the careful negotiation that is required of the teacher educator if the use of the lesson observation form is to accommodate the desired culturally situated view of the skills and behaviour of the student teacher. The integration that Davis describes does not proceed at an even or predictable pace, and the scepticism with which she earlier regarded the lesson observation form reflects her knowledge that the developmental object of teacher education does not map easily onto political rules. For the tool to be employed meaningfully to stimulate student teachers' learning, the teacher educator must therefore work between different levels of abstraction in relation to different objects and different members of the communities involved (including, in the example above, children in the classroom of the student teacher). In this extended analysis of the use of a lesson observation form, simultaneous work has thus been shown to be taking place in several different activity systems, in which the tool being used has several different layers of meaning: the mediation of student teacher learning; maintaining the relationship with the school through the professional development of the mentor; and providing evidence towards the reputation of the university for the purpose of quality assurance. In the absence of the expert orchestration by the teacher educator of these contradictions, only the artefact is likely to obtain ontological status.

\section{Transforming teacher education}

Cultural-historical activity theory offers a non-reductionist view of human activity as being rooted in material social practices that produce (and are produced by) social interactions and human subjectivity (Stetsenko and Arievitch 2005). Avoiding the so-called narrower analysis of a 'mentalist paradigm that limits the self to individual mental constructs' (ibid., 477), activity theory offers a framework for considering both the mediated nature of the subject-object relationship in teacher education, as well as the mediated nature of certain material artefacts. Miettinen (2001) draws attention to tools as human creations that over time become imbued with particular norms and rules. While tools mediate the relationship between subject and object, it is the community that mediates the relationships between subjects and tools, determining how they are used and the ways in which they afford or indeed constrain the agency of participants in an activity system (Roth and Tobin 2002). We have focused in this paper on the use of a tool which threatened to deflect teacher educators from their desired object. For the teacher educators in the study, the tool appeared to imply a philosophy based on a managerialist need to control and 
standardise, an agenda which denies agency and is delivered instead 'through target setting, monitoring and disciplining of the teaching profession' (Shain and Ozga 2001, 117). Our participants tended to regret policy-determined changes in their role towards quality assurance and away from higher-level teaching, a general cultural trend which has been said to be trivializing the work of teacher education (Johnson et al. 2005). We therefore agree with Zeichner (2006) in thinking that the projection by the policy community of formal standards as the route to quality will continue to interfere with the broader conversations about the work of teacher education and the development of practice that should be taking place.

Activity theory seeks to be developmental as well as explanatory. It configures transformative practices as 'being the condition necessary to sustain the development of people and of their creations' (Stetsenko \& Arievitch 2005, p.498). According to Steinnes (2004, p. 270), this is a plural and highly contingent form of transformation which requires that:

we as pedagogues or academics concerned with practice problems in the educational institutions of society might identify our position and our task to be that of taking part in finding new grounds for pedagogical practice.

This process does not simply envisage new forms of practice, it also insists that we explore contradictions in current systems for the possibility of new formulations of identity and a reorganisation of the division of labour (Avis, 2009). In the context of the present study, we have reason to think that partnership teacher education - in which schools work with universities to train teachers - works. Indeed, from our research, schools seem to need HE tutors to make the system work effectively (Ellis et al. 2011). But there is also evidence of a lack of a view of the future of teacher education as functioning as a form of professional education within universities. HEI expectations of teacher education as academic work have been shown to be fairly narrow (Ellis et al. 2012); teachers educators, we have noted, are perceived to be 'semi-academics'; the current trend for the diversification of provision has not been characterised by a coherent vision of what teacher education is 'about'. Although partnerships are clearly vital for some fairly obvious, common sense reasons, schools are mature organisations in terms of teacher education and professional development just as universities are mature in their capacity for research and 
knowledge mobilisation. It may be time for the roles and responsibilities within partnerships to be redefined.

Engeström (1999) reminds us that human beings participate in potentially conflicting activity systems, and that it is in working towards the resolution of contradictions within an activity system or at the site of a cluster of adjoining activity systems that transformational understanding is revealed (Avis 2009). Our analysis of the cultural and historical processes which underpin teacher educators' activities as individuals and their professional representations as members of an academic organisation has focused on the artefacts that mediate practice. The data collected showed that in all but one case, the artefacts came from a professional rather than an educational research context. In spite of expectations across higher education, photographs and descriptions of our participants' bookshelves and work spaces revealed little or nothing of the paraphernalia of research. In what appears to be a primary contradiction of the work, research was an activity that the teacher educators in our sample were subtly not quite a part of. Alloway, for example, spoke for the majority when she said:

I'm still trying to make sense of my own institution [...] there seem to be two sorts of people: there seem to be the people, they're called the 'engine room', the people who teach the students $[\ldots]$ And then there is another set of people who do research $[. .$.$] and$ they're sort of these two separate pots of people. Now there is some overlap between them, there are some links between them, so I'm one of the engine room people, and certainly I'm encouraged to do research... not insisted upon, but I'm encouraged. And indeed I want to and I've already started some [...] You know there are sessions which are run by various people on writing, on researching, and they're just open and you just go along if you want to.

Although teacher educators are well aware of the need to do research, and would generally want to do research, there tends to be little acknowledgement by universities of their different background and specific developmental needs. There are examples of helpful colleagues and informal support but little in the way of dedicated resource to help them through this area of work. The preponderance of artefacts from the professional context indicates a highly 
conscientious commitment to teaching at the expense it seems of time for research. Perhaps this level of commitment is more than is necessary within partnership teacher education, and reveals one aspect of the difficulty of adapting to a different culture, or of even making sense of the crucial difference that research might make to the balance of work which must increasingly meet multiple tests of rigour and relevance in intersecting research, practice, public scrutiny and usefulness.

The increasing emphasis on research in higher education, with implications for status and funding, have brought increasing pressure on academic staff (Rowlinson et al. 2010). This pressure is undeniably much greater on those appointed without a research background, a category to which teacher educators almost invariably belong. While expertise in teaching might provide some sense of security and commitment, the relentless linearity of political consolidation as well as the indeterminate evolution of any one approach to teacher education continues to erode the status of the work as a necessary function of higher education. If we as pedagogues and academics are to find new grounds for pedagogical practice, it will almost certainly depend on 'critical perspectives on these societal practices in which we participate, and on our own socialindividual basis to act and to reflect on the problems and conflicts to be resolved' (Langemeyer and Roth in Avis 2009, 162). The research active teacher educator can no longer afford to be a contradiction in terms.

\section{References}

Acker, S. 1997. Becoming a teacher educator: voices of women academics in Canadian faculties of education. Teaching and Teacher Education, 13:1 54-72.

Acker, S. and J.-A. Dillabough. 2007. Women 'learning to labour' in the 'male emporium': exploring work in teacher education. Gender and Education, 19:3 297 - 316.

Avis, J. 2009. Transformation or transformism: Engeström's version of activity theory? Educational Review. 61:2 151-165. 
Bakhurst, D. 2009. Reflections on activity theory. Educational Review 61:2 197-210.

Berger, M. and T. Kostal. 2002. Financial resources, regulation, and enrollment in US public higher education. Economics of Education Review. 21:1 101-110.

Christie, F., T. Conlon, T. Gemmell, and A. Long. 2004. Effective partnership? Perceptions of PGCE student teacher supervision. European Journal of Teacher Education 27:2 109-123.

Christie, D., M. Donoghue, G. Kirk, O. McNamara, I. Menter, G. Moss, J. Noble-Rogers, A. Oancea, C. Rogers, P. Thomson, and G. Whitty. 2012. Prospects for Education Research in Education Departments in Higher Education Institutions in the UK, Report from the BERAUCET Working Group on Education Research.

Clifford, G. J. and J. W. Guthrie. 1988. Ed school. A Brief for professional education. Chicago: University of Chicago Press.

Cole, M. 1996. Cultural psychology: the once and future discipline, Cambridge MA: The Belknap Press of Harvard University.

Cole, M. and Y. Engeström. 1993. A cultural-historical approach to distributed cognition. In G. Salomon (Ed.), Distributed cognitions (pp. 1-46). New York: Cambridge University Press.

CRADLE. 200). The Activity System. Available from:

http://www.helsinki.fi/cradle/activitysystem.htm. [Accessed 23/08/2012].

Creswell, J. W. 2002. Educational research: Planning, conducting, and evaluating, quantitative and qualitative research. Upper Saddle River, NJ: Pearson Education.

Cuban, L. 1999. How scholars trumped teachers. Change without reform in university curriculum, teaching and research, New York, NY: Teachers College Press. 
Darling-Hammond, L. 2006. Powerful teacher education: lessons from exemplary programs, Jossey-Bass: San Francisco: CA.

Day, C. 1995. Qualitative research, professional development and the role of teacher educators: fitness for purpose. British Educational Research Journal. 21:3 357-369.

Department for Education (DfE). 2010. The Importance of Teaching. The Schools White Paper, November 2010, Cm 7980. Accessed 6 December 2011 at www.education.gov.uk/publications/eOrderingDownload/CM-7980.pdf DfE (2011a) Training our next generation of outstanding teachers. A discussion paper. Department for Education, June.

Department for Education (DfE). 2011. Training our next generation of outstanding teachers. The implementation plan for the ITT strategy. Department for Education, November. Accessed 6 December 2011 at

http://media.education.gov.uk/assets/files/pdf/t/training\%20our\%20next\%20generation\%20of\%2 0outstanding\%20teachers\%20nov\%202011.pdf.

Dillabough, J.A. and S. Acker. 2002. Globalisation, women's work and teacher education: A cross-national analysis. International Studies in Sociology of Education 12,3: 227-260.

Donaldson, G. 2011. Teaching Scotland's Future. Edinburgh: The Scottish Government.

Ducharme, E. R. 1993. The lives of teacher educators. New York, NY: Teachers College Press.

Edwards, A. 2011. Cultural Historical Activity Theory, British Educational Research Association online resource. Accessed 27 August 2012 at http://www.bera.ac.uk/resources/cultural-historicalactivity-theory-chat.

Edwards, A. and H. Daniels. 2004. Editorial: Using Sociocultural and Activity Theory in Educational Research, Educational Review, 56:2 107-111. 
Ellis, V., A. Blake, J. McNicholl, and J. McNally. 2011. The work of teacher education, the Final Report for The Higher Education Academy, Subject Centre for Education, ESCalate.

Ellis, V., J. McNicholl, and A. Pendry. 2012. 'Institutional conceptualisations of teacher education as academic work in England'. Teaching and Teacher Education. 28: 685 - 693.

Enders, J. 2000. Academic staff in Europe: Changing Employment and Working Conditions. In M. Tight (Ed.), Academic work and life: What it is to be an academic, and how this is changing. Amsterdam: JAI/Elsevier Science.

Engeström, Y. 1987. Learning by Expanding: An Activity-theoretical Approach to Developmental Research, Orienta-Konsultit, Helsinki.

Engeström, Y. 1999. Activity theory and individual and social transformation. In: Y. Engeström, R. Miettinen \& R.-L. Punamaki (Eds.), Perspectives on activity theory, Cambridge: Cambridge University Press.

Engeström, Y., R. Miettinen, and R. L. Punamäki, eds. 1999. Perspectives on Activity Theory, Cambridge: Cambridge University Press.

Engeström, Y. 2005. Developmental Work Research: Expanding Activity Theory in Practice. Lehmanns Media, Berlin.

Foot, K.A. 2001. Cultural historical activity theory as Practical Theory: Illuminating the Development of a Conflict Monitoring Network, Communication Theory, 11:1 55-83.

Harley, S. 2003. Research Selectivity and Female Academics in UK universities: from gentleman's club and barrack yard to smart macho? Gender and Education. 15:4 377-390.

Harrison, J. K. and F. McKeon. 2008. The formal and situated learning of beginning teacher educators in England: identifying characteristics for successful induction in the transition from 
workplace in schools to workplace in higher education. European Journal of Teacher Education. 31:2 151-168.

Hartley, D. 2009. Education policy, distributed leadership and socio-cultural theory. Educational Review. 61:2 139-150.

Higher Education Statistics Agency (HESA). 2009. Resources of Higher Education Institutions, Cheltenham.

Higher Education Funding Council for England (HEFCE). 2009a. Research Assessment Exercise 2008: Summary statistics Panel K. Accessed 12 July 2012 at http://www.rae.ac.uk/pubs/2009/ov/

Higher Education Funding Council for England (HEFCE). 2009b. Research Assessment Exercise 2008: Sub-panel 45 Education. Subject Overview Report. Accessed 12 July 2012 at http://www.rae.ac.uk/pubs/2009/ov/

Holligan, C., M. Wilson and W. Humes. 2011. Research cultures in English and Scottish university education departments: An exploratory study of academic staff perceptions. British Educational Research Journal. 37:4 713-734.

Iven, H. 1994. Teachers should be trained in partnership. Teaching Today. Spring 24-25.

Johnson, D. D., B. Johnson, S.J. Farenga, and D. Ness, D. 2005. Trivializing teacher education: The accreditation squeeze. Lanham, MD: Rowan \& Littlefield.

Kaptelinin, V. and R. Miettenen. 2005. Introduction: perspectives on the object of activity, Mind, Culture and Activity. 12:1 1-3.

Kosnick, C. and C. Beck. 2008. In the shadows: non-tenure-line instructors in pre-service teacher education. European Journal of Teacher Education. 31:2 185-202. 
Leontiev, A. 1978. Activity, consciousness, and personality. Englewood Cliffs, NJ: Prentice Hall.

Liston, D.P. 1995. Work in Teacher Education. A Current Assessment of US Teacher Education. In Holowinsky, I.Z. \& Shimahara, N. K. (Eds). Teacher Education in Industrialised Nations: Issues in Changing Social Contexts. New York: Garland Publishing.

Maguire, M. 1994. The place of women in teacher education: discourses of power. Educational Review. 46:2 121-139.

Mahony, P. and I. Hextall. 2001. Performing and conforming, in: D. Gleeson \& C. Husbands (Eds). The performing school: managing, teaching and learning in a performance culture. London, Routledge Falmer.

Martin, D. and N. Peim. 2009. Critical perspectives on activity theory. Educational Review. 61:2 131-138.

McNamara, O., M. Brundrett. and R. Webb. 2008. Primary Teachers: Initial teacher education, continuing professional development and school leadership development (Primary Review Research Survey 6/3. Cambridge: University of Cambridge Faculty of Education.

Menter, I., M. Hulme, D. Elliot, J. Lewin, V. Baumfield, A. Britton, M. Carroll, K. Livingston, M. McCulloch, I. McQueen, F. Patrick, and A. Townsend. 2010. Literature Review on Teacher Education in the 21st Century. The Scottish Government. Accessed 8 December 2011 at www.scotland.gov.uk/Resource/Doc/325663/0105011.pdf.

Menter, I. and K. Lowden 2012. Teacher Education Clinical Model 2012: Final evaluation report. Glasgow: University of Glasgow.

Miettinen, R. 2001. Artifact Mediation in Dewey and in Cultural Historical Activity Theory. Mind, Culture, and Activity. 8:4 297-308. 
Mills, D., A. Jepson, T. Coxon, M. Easterby-Smith, P. Hawkins, and J. Spencer. 2006.

Demographic Review of the UK Social Sciences (Swindon, Economic and Social Research Council).

Murray, J. 2002. Between chalkface and the ivory towers? A study of the professionalism of teacher educators working on primary initial teacher education courses in the English education system, Collected Original Resources in Education (CORE). 26:3 1-503.

Murray, J. 2005. Addressing the Priorities: New Teacher Educators and Induction into Higher Education. Journal of Teacher Education. 28:1 67-85.

Murray, J. and T. Male. 2005. Becoming a teacher educator: evidence from the field. Teaching and Teacher Education. 21: 125-142.

Murray, J., A. Campbell, I. Hextall, M. Hulme, M. Jones, P. Mahony, I Menter, R. Procter and K. Wall. 2009. Research and teacher education in the UK: Building capacity. Teaching and Teacher Education. 25:7 944-950.

Onwuegbuzie, A. J. and N. L. Leech. 2007. Validity and Qualitative Research: An Oxymoron? Quality \& Quantity. 41: 233-249.

Reeves, J. and N. Boreham. 2006. What's in a vision? Introducing an Organisational Learning Strategy in a Local Authority's Education Service. Oxford Review of Education. 32:4, 467-486.

Roth, W. and K. Tobin. 2002. Redesigning an "Urban" Teacher Education Program: An Activity Theory Perspective. Mind, Culture, and Activity. 9:2 108-131.

Rowlinson, M., J. Hassard, and S. Mohun. 2010. Research Audits and their Financial Consequences. In B. Lee (Ed.) Challenges and Controversies in Management Research. London, Taylor and Francis. 
Russell, B. and J. Chapman. 2001. Working as partners: school teachers' experiences as university-based teacher educators. Asia-Pacific Journal of Teacher Education. 29:3 235-247.

Slaughter, S., and G. Rhoades. 2004. Academic capitalism and the new economy. Markets, state, and higher education. Baltimore, Md: The Johns Hopkins University Press.

Schuster, J.H. and M. J. Finkelstein. 2008. The American Faculty: The Restructuring of Academic Work and Careers, Baltimore, Md: Johns Hopkins University Press.

Shain, F. and J. Ozga. 2001. 'Identity crisis? Problems and issues in the sociology of education', British Journal of Sociology of Education, 22(1), 109-20.

Smith, K. 2005. Teacher educators' expertise: what do novice teachers and teacher educators say? Teaching and Teacher Education. 21: 177-192.

Steinnes, J. 2004. Transformative education in a poststructuralist perspective. Journal of Transformative Education 2(4) 261-75.

Stetsenko, A. 2005. Activity as object-related: resolving the dichotomy of individual and collective planes of activity, Mind, Culture, and Activity, 12(1), 70-88.

Stetsenko, A. and I. M. Arievitch. 2005. The Self in Cultural-Historical Activity Theory: Reclaiming the Unity of Social and Individual Dimensions of Human Development, Theory and Psychology, 14(4), 475-503.

Stronach, I. and B. Morris. 2009. Polemical notes on educational evaluation in the age of 'policy hysteria'. Evaluation \& Research in Education. 8:1 5-19.

Tierney, W.G. 2001. Faculty of Education in a Period of Systemic Reform. In Tierney, W.G. (Ed.), Faculty Work in Schools of Education: Rethinking Roles and Rewards for the Twenty-first Century. Albany, State University of New York Press. 
Vygotsky, L. 1986. Thought and language (A. Kozulin, Ed. \& Trans.). Cambridge, MA: MIT Press.

Wertsch, J. 1998. Mind as action. New York: Oxford University Press.

Wertsch, J. 2007. Mediation. In H. Daniels, M. Cole, \& J. Wertsch (Eds), The Cambridge Companion to Vygotsky, Cambridge: Cambridge University Press.

Xu, Z., J. Hannaway, and C. Taylor. 2011. Making a difference? The effects of Teach For America in high school. Journal of Policy Analysis and Management. 30:3 447-469.

Zeichner, K. 2006. Studying teacher education programs: Enriching and enlarging the inquiry. In C. Conrad \& R. Serlin (Eds.). The Sage handbook on research in education (pp. 79-94). Thousand Oaks, CA: Sage. 